\title{
Biosynthesis and actions of 5-oxoeicosatetraenoic acid (5-oxo-ETE) on feline granulocytes ${ }^{1}$
}

Chantal Cossette ${ }^{\mathrm{a}}$, Sylvie Gravel ${ }^{\mathrm{a}}$, Chintam Nagendra Reddy ${ }^{\mathrm{b}}$, Vivek Gore ${ }^{\mathrm{b}}$, Shishir Chourey ${ }^{\mathrm{b}}$,

Qiuji Ye ${ }^{b}$, Nathaniel W. Snyder ${ }^{c}$, Clementina A. Mesaros ${ }^{c}$ Ian A. Blair ${ }^{c}$, Jean-Pierre Lavoie ${ }^{d}$,

Carol R. Reinero ${ }^{\mathrm{e}}$, Joshua Rokach ${ }^{\mathrm{b}}$, William S. Powell ${ }^{\mathrm{a}}$

a Meakins-Christie Laboratories, Centre for Translational Biology, McGill University Health

Centre, 1001 Decarie Blvd, Montreal QC H4A 3J1, Canada

${ }^{\mathrm{b}}$ Claude Pepper Institute and Department of Chemistry, Florida Institute of Technology,

Melbourne, Florida 32901-6982

c Center for Cancer Pharmacology, University of Pennsylvania, 854 BRB II/III, 421 Curie Blvd., Philadelphia, PA 19104-6160

${ }^{d}$ Dept. of Clinical Sciences, Faculty of Veterinary Medicine, Université de Montréal, 3200 rue Sicotte, St-Hyacinthe J2S 6C7, QC, Canada

e Department of Veterinary Medicine and Surgery, University of Missouri, 900 E Campus Drive, Columbia, MO 65211, USA

\section{E-mail addresses:}

Chantal Cossette: chantal.cossette@mcgill.ca

Sylvie Gravel: sylvie.gravel@mcgill.ca

Chintam Nagendra Reddy: nchintam@ fit.edu

Vivek Gore: vivek.gore@navinta.com

Shishir Chourey: schourey2012@my.fit.edu

Qiuji Ye: qye2012@my.fit.edu

Nathaniel W. Snyder: natewsnyder@gmail.com
Clementina A. Mesaros: mesaros @upenn.edu

Ian A. Blair: ianblair@ exchange.upenn.edu

Jean-Pierre Lavoie: jean-pierre.lavoie@ umontreal.ca

Carol Reinero: reineroc@ missouri.edu

Joshua Rokach: jrokach@ @it.edu

William S. Powell: william.powell@ mcgill.ca

\section{Corresponding author}

William S Powell, Meakins-Christie Laboratories, Centre for Translational Biology, McGill University Health Centre, 1001 Decarie Blvd, Montreal QC H4A 3J1, Canada

Tel: 514-934-1934 ext 76414

Fax|: Not operational (new building)

E-mail: william.powell@ mcgill.ca 
${ }^{1}$ WSP and JR hold a patent on OXE receptor antagonists related to compounds 230 and 264 (Powell WS and Rokach J, 5-Oxo-ETE receptor antagonist compounds, US patent US-20140323535-A1 (2014)) 


\begin{abstract}
The 5-lipoxygenase product 5-oxo-6,8,11,14-eicosatetraenoic acid (5-oxo-ETE) is the most powerful human eosinophil chemoattractant among lipid mediators and could play a major pathophysiological role in eosinophilic diseases such as asthma. Its actions are mediated by the OXE receptor, orthologs of which are found in many species from humans to fish, but not rodents. The unavailability of rodent models to examine the pathophysiological roles of 5-oxoETE and the OXE receptor has substantially hampered progress in this area. As an alternative, we have explored the possibility that the cat could serve as an appropriate animal model to investigate the role of 5-oxo-ETE. We found that feline peripheral blood leukocytes synthesize 5oxo-ETE and that physiologically relevant levels of 5-oxo-ETE are present in bronchoalveolar lavage fluid from cats with experimentally induced asthma. 5-Oxo-ETE $\left(\mathrm{EC}_{50}, 0.7 \mathrm{nM}\right)$ is a much more potent activator of actin polymerization in feline eosinophils than various other eicosanoids, including leukotriene (LT) $\mathrm{B}_{4}$ and prostaglandin $\mathrm{D}_{2}$. 5-Oxo-ETE and $\mathrm{LTB}_{4}$ induce feline leukocyte migration to similar extents at low concentrations $(1 \mathrm{nM})$, but at higher concentrations the response to 5-oxo-ETE is much greater. Although high concentrations of selective human OXE receptor antagonists blocked 5-oxo-ETE-induced actin polymerization in feline granulocytes, their potencies were about 200 times lower than for human granulocytes. We conclude that feline leukocytes synthesize and respond to 5-oxo-ETE, which could potentially play an important role in feline asthma, a common condition in this species. The cat could serve as a useful animal model to investigate the pathophysiological role of 5-oxo-ETE.
\end{abstract}

\title{
KEYWORDS
}

5-Lipoxygenase; OXE receptor; Eicosanoids; Eosinophils; Neutrophils; Inflammation 


\section{Introduction}

5-Oxo-6,8,11,14-eicosatetraenoic acid (5-oxo-ETE) is produced by the 5-lipoxygenase (5-LO) pathway along with leukotrienes (LTs) $\mathrm{B}_{4}, \mathrm{C}_{4}, \mathrm{D}_{4}$, and $\mathrm{E}_{4}$. It is formed by 5-hydroxyeicosanoid dehydrogenase (5-HEDH), which oxidizes 5S-hydroxy-6,8,11,14-eicosatetraenoic acid (5SHETE) in the presence of NADP ${ }^{+}$[1] (Fig. 1). 5-HEDH is highly selective for both 5S-HETE and $\mathrm{NADP}^{+}$and is found in most types of inflammatory cells as well as in platelets, endothelial cells, epithelial cells, and many cancer cell lines [2]. Its synthesis is dependent on the availability of both $5 \mathrm{~S}-\mathrm{HETE}$ and NADP ${ }^{+}$, which is normally present at very low concentrations within cells [3]. Conditions that promote the oxidation of NADPH to $\mathrm{NADP}^{+}$, including activation of the respiratory burst in phagocytic cells, oxidative stress, and cell death, strongly enhance 5-oxo-ETE synthesis [4-6].

5-Oxo-ETE is a potent chemoattractant for human eosinophils [7] and neutrophils [8]. Although it is not as potent as $\mathrm{LTB}_{4}$ in inducing neutrophil migration, it is the only 5-LO product with appreciable chemoattractant effects on human eosinophils, with the exception of its 15-LOgenerated metabolite 5-oxo-15-HETE, which, although less potent than 5-oxo-ETE, acts by the same OXE receptor [7, 9, 10]. 5-Oxo-ETE also elicits a variety of other responses in neutrophils and eosinophils, including calcium mobilization, actin polymerization, CD11b expression, degranulation, and superoxide production $[2,11,12]$. It also promotes the transmigration of eosinophils across endothelial cell monolayers [13] as well as eosinophil infiltration into the skin when injected intradermally in humans [14].

As is the case for other 5-LO products, the actions of 5-oxo-ETE are mediated by a G proteincoupled receptor. The OXE receptor for 5-OXo-ETE is encoded by the OXERI gene [15] and was 
identified independently by three groups as a 423 amino acid-containing protein [16-18]. It is expressed very highly on eosinophils and basophils and to a lesser extent on neutrophils and monocytes/macrophages $[17,19,20]$. Although $O X E R l$ orthologs exist in many species, including several species of fish, this gene is not present in mice, rats, or guinea pigs. Because of the widespread use of the latter as animal models, this has significantly impeded progress in determining the pathophysiological role of 5-oxo-ETE. In contrast to rodents, cats have an OXER1 ortholog that would encode a protein of 422 amino acids that is $75 \%$ identical to the human OXE receptor. To determine whether the cat might be a suitable animal model to investigate the pathophysiological role of 5-oxo-ETE in eosinophilic diseases such as asthma, we examined the ability of feline leukocytes to respond to and to synthesize 5-oxo-ETE. We found that 5-oxo-ETE is a potent activator of feline eosinophils and neutrophils and that feline leukocytes synthesize 5-oxo-ETE.

\section{Materials and methods}

\subsection{Materials}

5-Oxo-ETE [21], 5-HETE [22], $\mathrm{LTB}_{4}$ [23], 230 [24], and 264 [24] were prepared by chemical synthesis as previously described. 13S-Hydroxy-9Z,11E-octadecadienoic acid (13-HODE), which was used as an internal standard for HPLC, was prepared by oxidation of linoleic acid with soybean lipoxygenase Type 1B (Sigma-Aldrich, Inc., St. Louis, MO) [25]. Arachidonic acid (AA) was obtained from Nuchek Prep Inc, Elysian, MN, and was purified by reversed-phase high performance liquid chromatography (RP-HPLC) before use. Prostaglandin $\mathrm{D}_{2}\left(\mathrm{PGD}_{2}\right)$ and A23187 were purchased from Cayman Chemical, Ann Arbor, MI and Calbiochem, LaJolla, CA, respectively. Phorbol myristate acetate (PMA), phenazine methosulfate (PMS), Gue1654 (7(methylthio)-2-[(2,2-diphenylacetyl)amino]benzo[1,2-d:4,3-d']bisthiazole), dichloromethane, 
$\mathrm{N}, \mathrm{N}$-diisopropylethylamine (DIPEA), and pentafluorobenzyl bromide (PFBBr) were obtained from Sigma-Aldrich, St. Louis, MO. LC-MS Optima grade hexanes, methanol, methyl-t-butyl ether, and isopropanol were obtained from Fisher Scientific (San Jose, CA).

\subsection{Preparation of feline peripheral blood leukocytes}

Feline blood (up to $5 \mathrm{~mL}$ per animal) was collected in heparinized tubes from animals housed at the Centre hospitalier universitaire vétérinaire, Université de Montréal, Saint-Hyacinthe, Quebec. The animals used in all parts of this study were a mixture of males and females. The protocol was approved by the ethics committee for the use of animals of the University of Montreal. Blood was mixed with a solution of dextran 500 (from Leuconostoc; Sigma-Aldrich) and the red cells were allowed to sediment under unit gravity at $4{ }^{\circ} \mathrm{C}$ for $45 \mathrm{~min}$. The supernatant was centrifuged and the cells in the pellet were subjected to hypotonic lysis to remove red cells. The resulting leukocyte fraction was suspended in phosphate-buffered saline (PBS) containing $\mathrm{NaCl}$ (137 $\mathrm{mM}), \mathrm{KCl}(2.7 \mathrm{mM}), \mathrm{KH}_{2} \mathrm{PO}_{4}(1.5 \mathrm{mM})$, and $\mathrm{Na}_{2} \mathrm{HPO}_{4}(8.1 \mathrm{mM})$ at a $\mathrm{pH}$ of 7.4 and used to investigate the biosynthesis of 5-oxo-ETE and its effects on calcium mobilization, actin polymerization, and cell migration as described below.

\subsection{Preparation of feline bronchoalveolar lavage (BAL) fluid supernatant and cells}

Cats with experimentally induced asthma were sensitized and challenged with Bermuda grass allergen as previously described [26] and briefly anesthetized for collection of BAL fluid. This part of the study was approved by the University of Missouri Animal Care and Use Committee. Lavage fluid was collected by feeding an 8 French red rubber catheter down a $4 \mathrm{~mm}$ endotracheal tube until gently wedged, instilling $20 \mathrm{~mL}$ sterile saline and gently aspirating. The BAL fluid was filtered by passing through a single layer of sterile gauze to remove mucus and the flow- 
through was subsequently centrifuged at $300 \mathrm{x} g$ for $10 \mathrm{~min}$. The supernatant was removed and stored at $-80{ }^{\circ} \mathrm{C}$ until analysis. A cytospin was performed on the cell pellet, stained with WrightGiemsa and a differential count performed. BAL cells $\left(1 \times 10^{6}\right.$ cells in $1 \mathrm{~mL}$ RPMI 1640 containing penicillin $(50 \mathrm{IU} / \mathrm{mL})$, streptomycin $(100 \mu \mathrm{g} / \mathrm{mL})$ amphotericin $\mathrm{B}(0.5 \mu \mathrm{g} / \mathrm{mL})$ and heat-inactivated FCS (10\%)) were plated in 6-well tissue culture plates for $2 \mathrm{~h}$ at $37^{\circ} \mathrm{C}$ in $5 \%$ $\mathrm{CO}_{2}$. Nonadherent cells were collected after gentle swirling and washing twice with RPMI 1640, pelleted, and viable cells counted on a hemocytometer using trypan blue (0.1\%). Adherent cells (alveolar macrophages) were detached by incubating $1 \mathrm{~mL}$ PBS containing EDTA (5 mM) for 5 min and aggressively pipetting up-and-down. Washed cells in PBS were counted as described above. AA metabolism by BAL cells was evaluated by incubating adherent and non-adherent cells $\left(5 \times 10^{5}\right.$ cells in $0.5 \mathrm{~mL}$ PBS containing $\mathrm{Ca}^{++}$and $\left.\mathrm{Mg}^{++}\right)$with $\mathrm{AA}(20 \mu \mathrm{M}), \mathrm{A} 23187(5 \mu \mathrm{M})$ and PMA $(100 \mathrm{nM})$ at $37{ }^{\circ} \mathrm{C}$. The incubations were terminated after $30 \mathrm{~min}$ by the addition of 0.5 $\mathrm{mL}$ methanol. The samples were stored at $-80{ }^{\circ} \mathrm{C}$ prior to RP-HPLC analysis.

\subsection{Measurement of 5-oxo-ETE by RP-HPLC}

To evaluate 5-HEDH activity, peripheral blood leukocytes $\left(2.5 \times 10^{6}\right.$ cells in $0.5 \mathrm{~mL}$ PBS containing $\mathrm{CaCl}_{2}(1.8 \mathrm{mM})$ and $\left.\mathrm{MgCl}_{2}(1 \mathrm{mM})\right)$ were preincubated for 5 min with phenazine methosulfate $(50 \mu \mathrm{M})$, followed by incubation with 5 S-HETE $(4 \mu \mathrm{M})$ for an additional 10 min. The incubations were terminated by the addition of ice-cold methanol $(0.33 \mathrm{~mL})$ and the products were analyzed by precolumn extraction-RP-HPLC [27] using a modified Waters 2695 Alliance system (Waters Corp., Mississauga, ON) with a photodiode array detector (Waters model 2996). The stationary phase was a Nova-Pak C18 column (Waters Corp) maintained at $35{ }^{\circ} \mathrm{C}$ and the mobile phase was a linear gradient between solvents A (water containing $0.02 \%$ HOAc) and B 
(acetonitrile containing 0.02\% HOAc) as follows: 0 min: $65 \% \mathrm{~B} ; 1.5 \mathrm{~min}: 65 \% \mathrm{~B} ; 6 \mathrm{~min}: 82 \% \mathrm{~B}$; 8 min: $82 \% \mathrm{~B}$. The flow rate was $1 \mathrm{~mL} / \mathrm{min} .13-\mathrm{HODE}(30 \mathrm{ng})$ was used as an internal standard.

\begin{abstract}
For evaluation of AA metabolism by BAL cells, the HPLC conditions were similar to those described above except that $\mathrm{PGB}_{2}(100 \mathrm{ng})$ was used as an internal standard and a more complex gradient was used: 0 min: water/acetonitrile/methanol/acetic acid (60:30:10:0.02); $40 \mathrm{~min}$ : water/acetonitrile/methanol/acetic acid (10:38:52:0.02). The flow rate was $1 \mathrm{~mL} / \mathrm{min}$.
\end{abstract}

\title{
2.5. Measurement of 5-oxo-ETE in BAL fluid by liquid chromatography/mass spectrometry
}

5-Oxo-ETE was measured in BAL fluid samples using 5-oxo-[11,12,14,15- $\left.{ }^{2} \mathrm{H}\right]$ ETE $\left(\mathrm{d}_{4}\right.$-5-oxoETE), synthesized as described previously [28], as an internal standard. Samples of BAL fluid were thawed and $\mathrm{d}_{4}$-5-oxo-ETE $(1 \mathrm{ng})$ was added to aliquots $(500 \mu \mathrm{L})$ of each sample, which were then extracted by addition of 4 volumes of methyl-t-butyl ether followed by $15 \mathrm{~min}$ of vigorous shaking and centrifugation at $3000 \mathrm{rpm}$ for $5 \mathrm{~min}$ at $4{ }^{\circ} \mathrm{C}$. The organic layer was transferred to a clean glass tube and evaporated to dryness under nitrogen gas. For absolute quantification of 5-oxo-ETE, a 10 point standard curve ranging from 0 to $1 \mathrm{ng}$ was generated by adding pure standards to PBS (pH 6.7; Invitrogen, Carlsbad, CA) followed by extraction as described above. Dried samples and standards were reconstituted in 5\% ethanol in hexanes (50 $\mu \mathrm{L}$ ) of which $20 \mu \mathrm{L}$ was injected. A Water's Alliance 2690 HPLC system was used for liquid chromatography separations. The PFB derivatives of 5-oxo-ETE and $\mathrm{d}_{4}$-5-oxo-ETE were separated using a normal phase Chiralpak AD-H column ( 250 x $4.6 \mathrm{~mm}, 5 \mu \mathrm{m}$ particle size; Daicel Chiral Technologies, Westchester, PA) with a $1 \mathrm{~mL} / \mathrm{min}$ flow rate modified from a previous method [29]. Solvent A was hexanes and solvent B was isopropanol/hexane (6:4; v/v). The composition of the gradient was: 0 min: $2 \% \mathrm{~B} ; 14.5 \mathrm{~min}: 2 \% \mathrm{~B} ; 15 \mathrm{~min}: 12 \% \mathrm{~B} ; 17 \mathrm{~min}$ : 
90\% B; 22 min: 90\%. For electron capture atmospheric pressure chemical ionization mass spectrometry a Thermo Triple Stage Quadrupole (TSQ Quantum) mass spectrometer (Thermo Scientific) with an APCI source was operated in negative ion mode as previously described [30]. The following transitions corresponding to each compound were monitored; 5-oxo-ETE-PFB, $\mathrm{m} / \mathrm{z} 317$ to 203 [collision energy (CE), $18 \mathrm{eV}$ ] and d $\mathrm{d}_{4}$-5-oxo-ETE-PFB, m/z 321 to 207 [(CE), 18 eV]. Data analysis was performed using Xcalibur software (Thermo Scientific). All values were interpolated from a linear standard curve $\left(y=0.0579 x+0.0056, r^{2}>0.99\right)$.

\subsection{Measurement of calcium mobilization in feline eosinophils and neutrophils}

Intracellular calcium levels were measured in feline peripheral blood granulocytes by modification of a method previously used for human cells [31]. Leukocytes $\left(10^{7}\right.$ cells $\left./ \mathrm{mL}\right)$ were treated with the acetoxymethyl ester of fluo-3 ( $2 \mu \mathrm{M}$; Life Technologies Inc, Burlington, Ontario) in the presence of Pluronic F-127 (0.02\%; Life Technologies) for 60 min at $23{ }^{\circ} \mathrm{C}$. Following centrifugation at $200 \mathrm{x}$ g for 10 min the pellet was resuspended in PBS to give a concentration of $50 \times 10^{6}$ cells $/ \mathrm{mL}$. The leukocytes were then treated with allophycocyanin-labeled mouse antihuman CD49d ( $2 \mu \mathrm{L} / 10^{6}$ cells; clone 9F10; BioLegend, San Diego, CA) for 30 min at $0{ }^{\circ} \mathrm{C}$. PBS $(1 \mathrm{~mL})$ was then added, the mixture centrifuged as described above, and the pellet resuspended in PBS to give a concentration of $2 \times 10^{6}$ leukocytes $/ \mathrm{mL}$. After incubation at $23{ }^{\circ} \mathrm{C}$ for $30 \mathrm{~min}$, an aliquot $(1 \mathrm{~mL})$ of the leukocyte suspension was removed and treated with PBS $(50 \mu \mathrm{L})$ containing $\mathrm{Ca}^{++}(36 \mathrm{mM})$ and $\mathrm{Mg}^{++}(20 \mathrm{mM})$. After $5 \mathrm{~min}$, the cells were analyzed by flow cytometry using a FACSCalibur instrument (Becton-Dickinson, San Jose, CA). Approximately $10^{6}$ cells were counted over 3 to 4 min for each sample. Fluo-3 fluorescence was measured in eosinophils and neutrophils, which were gated out on the basis of CD49d staining and side and 
forward scatter (see Fig. 5 below). Maximal calcium responses were determined by addition of A23187 $(10 \mu \mathrm{M})$ at the end of each run.

\subsection{Assessment of actin polymerization in feline eosinophils and neutrophils}

Polymerized F-actin was measured in leukocytes as described previously [24]. Peripheral blood leukocytes were treated with allophycocyanin-labeled anti-CD49d and suspended in PBS containing $\mathrm{Ca}^{++}(1.8 \mathrm{mM})$ and $\mathrm{Mg}^{++}(1 \mathrm{mM})$ at a concentration of $5 \times 10^{6}$ cells $/ \mathrm{mL}$. Aliquots $(100 \mu \mathrm{L})$ were incubated with either vehicle (PBS containing $\mathrm{Ca}^{++}, \mathrm{Mg}^{++}$, and $\left.0.1 \% \mathrm{BSA}\right)$ or different concentrations of eicosanoids for $20 \mathrm{~s}$, followed by the addition of formaldehyde (final concentration of $8.5 \%$ ). The cells were kept on ice for $30 \mathrm{~min}$ and then treated with a mixture of lysophosphatidylcholine (30 $\mu \mathrm{g}$ in $30 \mu \mathrm{L}$ PBS) and N-(7-nitrobenz-2-oxa-1,3-diazol-4yl)phallacidin (NBD-phallacidin; Life Technologies Inc; 40.8 pmol in $6.18 \mu \mathrm{L}$ methanol; final concentration, $0.3 \mu \mathrm{M}$ ). After being kept overnight in the dark at $4{ }^{\circ} \mathrm{C}$ the levels of $\mathrm{F}$-actin were evaluated by flow cytometry. Eosinophils were identified by high side scatter and high expression of CD49d, whereas neutrophils displayed lower side scatter and CD49d expression. To evaluate the effects of OXE antagonists cells were preincubated for 5 min with vehicle $(1 \mu \mathrm{L}$ DMSO) or different concentrations of 230,264 , or Gue1654 prior to the addition of 5-oxo-ETE $(10 \mathrm{nM})$.

\subsection{Evaluation of peripheral blood leukocyte migration}

Leukocyte migration was measured using 48-well microchemotaxis chambers (Neuro Probe Inc., Cabin John, MD) with Sartorius cellulose nitrate filters ( $8 \mu \mathrm{m}$ pore size; $140 \mu \mathrm{m}$ thickness; Neuro Probe Inc) [32]. Vehicle (PBS containing $\mathrm{Ca}^{++}, \mathrm{Mg}^{++}$and $0.3 \% \mathrm{BSA}$ ) or different concentrations of 5-oxo-ETE or $\mathrm{LTB}_{4}$ were added to the bottom wells, whereas leukocytes 
(150,000 cells in PBS containing $\mathrm{Ca}^{++}, \mathrm{Mg}^{++}$and $0.4 \%$ OVA) were added to each of the top wells. To investigate the effects of OXE receptor antagonists on cell migration either vehicle, 230 $(10 \mu \mathrm{M})$, or $264(10 \mu \mathrm{M})$ were added to both the top and bottom wells. After incubation for $2 \mathrm{~h}$ at $37{ }^{\circ} \mathrm{C}$ in $5 \% \mathrm{CO}_{2}$ and humidified air the cells were stained using hematoxylin (Canadawide Scientific, Ottawa, Ontario) followed by chromotrope 2R (Sigma Chemical Co) and the numbers of cells on the bottom surfaces were counted in five different fields at a magnification of 400x for each well. All incubations were performed in triplicate.

\subsection{Data analysis}

The statistical significance of differences was assessed by either ANOVA (Kruskal-Wallis oneway analysis of variance on ranks using Dunn's method as a multiple comparison procedure) or by Student's t-test as appropriate. The value of " $n$ " refers to the number of independent experiments performed on leukocytes or samples from different cats. In some cases (Fig. 6 and Fig. 8C), data are expressed as percentages of the maximal response to 5-oxo-ETE.

\section{Results}

Because of the limited quantities of feline blood available, we used a preparation of mixed peripheral blood leukocytes for all experiments on blood cells. These cells consisted of neutrophils $(26 \pm 3 \%)$ and eosinophils $(9 \pm 2 \%)$ with the remainder being mononuclear cells. In some cases, populations of eosinophils and neutrophils were identified using flow cytometry.

\subsection{Feline peripheral blood leukocytes and bronchoalveolar lavage cells synthesize 5-oxo-ETE.}

To determine whether feline leukocytes can synthesize 5-oxo-ETE, mixed peripheral blood leukocytes were incubated with 5S-HETE in the presence of PMS, which nonenzymatically 
converts intracellular NADPH to NADP ${ }^{+}$[33]. Analysis by RP-HPLC (Fig. 2A) revealed that 5SHETE was converted to a single product with a retention time $(6.34 \mathrm{~min})$ and UV spectrum $\left(\lambda_{\max }\right.$, $280 \mathrm{~nm}$; Fig. 2B) identical to those of authentic 5-oxo-ETE. The amount of 5-oxo-ETE formed under these conditions was $32 \pm 7$ pmol/10 6 leukocytes.

We also investigated the formation of 5-oxo-ETE by BAL cells obtained from cats with experimentally induced asthma in which allergen sensitization and challenge lead to the hallmark feature of airway eosinophilia. BAL cells were separated into two fractions based on adherence to plastic. Both adherent cells, which were mainly macrophages, and non-adherent cells, mainly eosinophils and neutrophils, converted AA to 5-LO products in the presence of the calcium ionophore A23187 and PMA (Fig. 3). In the case of adherent cells the main products were 5HETE and 5-oxo-ETE, along with smaller amounts of $\mathrm{LTB}_{4}(\mathrm{p}<0.05)$. We previously observed substantial amounts of 5-oxo-ETE compared to $\mathrm{LTB}_{4}$ in incubations with human monocytes, which display little $\omega$-oxidation activity, especially at longer time points [34]. Non-adherent cells produced greater amounts of 5-HETE than 5-oxo-ETE and $\mathrm{LTB}_{4}(\mathrm{p}<0.05)$. Although 5-oxoETE tended to be produced in larger quantities than $\mathrm{LTB}_{4}$, there was considerable variability among animals and this difference was not statistically significant. We did not observe $\omega-$ oxidation products of $\mathrm{LTB}_{4}$ in these experiments, although the conditions that we used were not optimized to measure these products and we cannot exclude the possibility that they were present. 


\subsection{Levels of 5-oxo-ETE in BAL fluid}

The concentrations of 5-oxo-ETE in BAL fluid supernatant fractions obtained from allergensensitized cats were measured by LC-MS-MS using deuterium-labelled 5-oxo-ETE as an internal standard (Fig, 4). The amounts of 5-oxo-ETE were determined from the ratios of the peak areas for $\mathrm{d}_{4}$-5-oxo-ETE (Fig. 4A) and endogenous unlabeled 5-oxo-ETE (Fig. 4B). The mean concentration of 5-oxo-ETE in feline BAL fluid was $0.41 \pm 0.11 \mathrm{nM}(\mathrm{n}=7)$.

\subsection{5-Oxo-ETE elicits calcium mobilization in feline peripheral blood eosinophils and neutrophils}

We examined the effects of 5-oxo-ETE on calcium mobilization in granulocytes using flow cytometry (Fig. 5). Since this assay requires larger numbers of cells than others, it was only possible to test a limited number of conditions. The cells were loaded with the calcium-sensitive dye fluo-3 and stained with anti-human CD49d prior to treatment with agonists. Eosinophils were identified principally by high levels of side scatter as well as by moderate CD49d staining (Fig. 5A). They were further gated on the basis of their low forward scatter properties (Fig. 5B). Neutrophils were identified on the basis of moderate forward and side scatter, as well as lower staining with anti-CD49d (Figures 5A and 5C).

5-Oxo-ETE $(10 \mathrm{nM})$ elicited a very strong biphasic calcium response in feline eosinophils, consisting of an initial spike followed by a second peak about $15 \mathrm{~s}$ later (Fig. 5D). This pattern was consistently observed with eosinophils from all of the cats tested. $\mathrm{PGD}_{2}(100 \mathrm{nM})$ also rapidly induced calcium mobilization in feline eosinophils, but to a lesser extent than 5-oxo-ETE and a secondary peak was not observed (Fig. 5E). 5-Oxo-ETE elicited a single peak of cytosolic calcium in neutrophils, but the response was less intense than with eosinophils (Fig. 5F). In 
contrast, $\mathrm{PGD}_{2}$ did not alter intracellular calcium levels in neutrophils (Fig. 5G). $\mathrm{LTB}_{4}(10 \mathrm{nM})$ (Fig. 5I) also mobilized intracellular calcium in eosinophils to an extent similar to $\mathrm{PGD}_{2}$ (Fig. 5I) but weaker than that induced by 5-oxo-ETE (Fig. $5 \mathrm{H}$ ). In contrast, $\mathrm{LTB}_{4}$ induced a stronger (monophasic) response in neutrophils (Fig. 5K) than 5-oxo-ETE (Fig. 5J).

\subsection{5-Oxo-ETE is a potent stimulator of actin polymerization in feline peripheral blood granulocytes}

The effects of 5-oxo-ETE, $\mathrm{LTB}_{4}$, and $\mathrm{PGD}_{2}$ on actin polymerization in feline granulocytes were evaluated in anti-CD49d-labeled leukocytes by flow cytometry, following staining of polymerized F-actin with NBD-phallacidin. 5-Oxo-ETE was a highly potent stimulator of actin polymerization in eosinophils with an $\mathrm{EC}_{50}$ of $0.72 \pm 0.19 \mathrm{nM}$ and was considerably more potent than both $\mathrm{LTB}_{4}\left(\mathrm{EC}_{50}, 60 \pm 31 \mathrm{nM}\right)$ and $\mathrm{PGD}_{2}\left(\mathrm{EC}_{50}, 14 \pm 2 \mathrm{nM}\right)(\mathrm{p}<0.05)$ (Fig. 6A), In contrast, $\mathrm{LTB}_{4}$ appeared to be more potent in stimulating actin polymerization in neutrophils $\left(\mathrm{EC}_{50}, 0.3 \pm 0.05 \mathrm{nM}\right)$ compared to 5-oxo-ETE $\left(\mathrm{EC}_{50}, 2.7 \pm 1.2 \mathrm{nM}\right)$, but this difference was not statistically significant. $\mathrm{PGD}_{2}$ had no effect on actin polymerization in neutrophils.

\subsection{5-Oxo-ETE is a chemoattractant for feline leukocytes}

The effects of 5-oxo-ETE and $\mathrm{LTB}_{4}$ on the migration of unfractionated peripheral blood leukocytes were evaluated using modified Boyden chambers (Fig. 6C). At the lowest concentration tested $(1 \mathrm{nM}), 5$-oxo-ETE and $\mathrm{LTB}_{4}$ induced similar degrees of leukocyte migration. However, the maximal response to 5-oxo-ETE was about 3 times greater than that to $\mathrm{LTB}_{4}(\mathrm{p}<0.05)$. The $\mathrm{EC}_{50}$ for $\mathrm{LTB}_{4}(1.2 \pm 0.4 \mathrm{nM})$ was significantly lower than that for 5-oxoETE $(24 \pm 16 \mathrm{nM})(\mathrm{p}<0.05)$. There was considerable variability in the response to $\mathrm{LTB}_{4}$, possibly related to variations in the cellular composition of leukocyte fractions among cats. 


\subsection{Human OXE receptor antagonists have only weak effects on feline granulocytes}

We previously identified two indole derivatives (compounds 230 and 264; Fig. 7) as potent OXE receptor antagonists that selectively block the effects of 5-oxo-ETE on human eosinophils and neutrophils with $\mathrm{IC}_{50}$ values of about $30 \mathrm{nM}$ [24]. To determine whether these compounds are active against the feline OXE receptor we investigated their effects on 5-oxo-ETE-induced actin polymerization. At concentrations of $1 \mu \mathrm{M}$, which nearly completely blocked the responses to 5oxo-ETE in human eosinophils and neutrophils, neither antagonist inhibited 5-oxo-ETE-induced actin polymerization in either eosinophils (Fig. 8A) or neutrophils (Fig. 8B). However, both antagonists had inhibitory effects at higher concentrations. The $\mathrm{IC}_{50}$ values for $\mathbf{2 3 0}$ for inhibition of 5-oxo-ETE-induced actin polymerization in eosinophils and neutrophils were respectively $10 \pm$ 3 and $7 \pm 3 \mu \mathrm{M}$, whereas the corresponding values for 264 were $6 \pm 2$ and $5 \pm 2 \mu \mathrm{M}$. In contrast, another OXE receptor antagonist, Gue1654 [35], at concentrations up to $30 \mu \mathrm{M}$, had no effect on the response to 5-oxo-ETE (data not shown).

\footnotetext{
We also tested the effects of OXE receptor antagonists on 5-oxo-ETE-induced leukocyte migration. In this case a single concentration $(10 \mu \mathrm{M})$ of antagonist was added to both the top and bottom wells. Neither antagonist had an appreciable effect on the concentration-response curve to 5-oxo-ETE (Fig. 8C).
} 


\section{Discussion}

To determine whether feline leukocytes possess 5-HEDH activity we examined the ability of feline peripheral blood leukocytes to convert 5S-HETE to 5-oxo-ETE in the presence of PMS. We previously showed that this is an excellent means of assessing 5-HEDH activity in intact cells, as PMS efficiently nonenzymatically converts intracellular NADPH to NADP ${ }^{+}$[4]. The intracellular ratio of $\mathrm{NADP}^{+}$to $\mathrm{NADPH}$ is critical in regulating 5-oxo-ETE synthesis [3], as it is very low in resting unstimulated cells in order to maintain a reducing environment to protect against excessive oxidative stress. Similar results were obtained with PMA (data not shown), which triggers the respiratory burst in phagocytic cells, strongly stimulating 5-oxo-ETE synthesis $[3,36]$. These experiments clearly reveal the presence of 5-HEDH activity in feline leukocytes. However, the amounts of 5-oxo-ETE synthesized were about 5-10 times less that what we previously observed with human monocytes and neutrophils under similar conditions [3]. Although this could be in part due to the fact that we used unfractionated leukocytes (about 35\% granulocytes) in the present study because of the limited quantities of feline blood available, it seems likely that feline leukocytes do have a lower capacity to synthesize 5-oxo-ETE compared to human cells. Additionally, we evaluated 5-oxo-ETE synthesis by BAL cells from cats sensitized and challenged with Bermuda grass allergen to induce airway inflammation, characterized by increases in eosinophils and other activated inflammatory cells. Both adherent (i.e. macrophages) and nonadherent (mainly eosinophils with smaller percentages of neutrophils) BAL cells synthesized 5-oxo-ETE along with smaller amounts of $\mathrm{LTB}_{4}$. Furthermore, BAL fluid from cats with experimentally induced asthma contained significant amounts of 5-oxo-ETE as measured by LC-MS. This would be consistent with a role for this substance in allergic airways disease in cats, a species that serves as a large animal pre-clinical model for human allergic 
asthma. To our knowledge this is the first report of the presence of 5-oxo-ETE in BAL fluid from any species.

Because of the small quantities of blood available it was not practical to separate different fractions of leukocytes prior to evaluation of their responses. However, by using flow cytometry we were able to gate out both eosinophils and neutrophils. We have previously shown that both 5-oxo-ETE and $\mathrm{LTB}_{4}$ induce calcium transients and actin polymerization in both of these cell types from humans [2], whereas $\mathrm{PGD}_{2}$ induces these responses in eosinophils but not neutrophils [37]. 5-Oxo-ETE and $\mathrm{PGD}_{2}$ are both chemoattractants for human eosinophils, with 5-oxo-ETE inducing a much stronger response [37]. Although $\mathrm{LTB}_{4}$ is capable of inducing various responses in human eosinophils [38], it does not have significant chemoattractant effects on these cells [7]. Therefore it was important to compare the effects of 5-oxo-ETE with those of $\mathrm{PGD}_{2}$ as well as $\mathrm{LTB}_{4}$ on eosinophil responses. 5-Oxo-ETE elicits a highly reproducible strong biphasic calcium response in feline eosinophils, in contrast to the simpler monophasic responses observed for $\mathrm{PGD}_{2}$ and $\mathrm{LTB}_{4}$. The initial rapid response, which was maximal by about $2 \mathrm{~s}$, is presumably due to activation of phospholipase $\mathrm{C}$ followed by $\mathrm{IP}_{3}$-mediated calcium mobilization in direct response to activation of the OXE receptor [39]. The second delayed response peaks about $15 \mathrm{~s}$ later and could possibly be due to secondary activation of store-operated calcium channels [40] on the eosinophil plasma membrane. Alternatively, 5-oxo-ETE could elicit the release of a second mediator from either eosinophils or neutrophils. For example, 5-oxo-ETE has been reported to activate $\mathrm{cPLA}_{2}$ in neutrophils and thereby stimulate the release of AA from these cells [41]. Both of these possibilities would explain the delay between the two calcium peaks. With human eosinophils we only observed a single monophasic rise in intracellular calcium levels [31]. In contrast to 5-oxo-ETE, $\mathrm{LTB}_{4}$ and $\mathrm{PGD}_{2}$ elicited simple monophasic increases in 
We were able to conduct more extensive experiments on actin polymerization in feline eosinophils and neutrophils because of the small numbers of cells required for these assays. 5Oxo-ETE is a very potent activator of actin polymerization in feline eosinophils, with an $\mathrm{EC}_{50}$ of about $0.7 \mathrm{nM}$, which is about 7 times lower than its $\mathrm{EC}_{50}$ for inducing the corresponding response in human eosinophils [42]. Furthermore, 5-oxo-ETE is at least 20 times more potent than PGD $_{2}$ and $\mathrm{LTB}_{4}$ in stimulating actin polymerization in feline eosinophils. The greater sensitivity of feline cells to 5-oxo-ETE should compensate for the lesser ability of feline leukocytes to synthesize this substance. The concentration of 5-oxo-ETE in BAL fluid (0.4 nM) is only slightly lower than its $\mathrm{EC}_{50}$ in activating eosinophils. Considering that 5-oxo-ETE in the airway lumen is considerably diluted by the saline used for lavage, this would suggest that biologically relevant concentrations of 5-oxo-ETE would be present in the lungs of the cats under study. These results, along with the potent chemoattractant effects of 5-oxo-ETE for feline granulocytes, would be 
consistent with a biological role for this eicosanoid in the cat, possibly as a proinflammatory mediator in feline asthma, which is a common disorder in this species [43].

5-Oxo-ETE induced a strong chemotactic response in feline leukocytes. At the lowest concentration tested $(1 \mathrm{nM})$ 5-oxo-ETE and $\mathrm{LTB}_{4}$ elicited similar responses, but at higher concentrations, the response to 5-oxo-ETE was considerably greater. Nevertheless, the $\mathrm{EC}_{50}$ for $\mathrm{LTB}_{4}$ was about 20 times lower than that for 5-oxo-ETE. The very intense response to 5-oxoETE was a little surprising, since the majority of granulocytes in the mixed leukocyte preparations that we used were neutrophils. However, substantial numbers of eosinophils were also present (about $25 \%$ of granulocytes) and the very strong response of these cells to 5-oxoETE may at least in part explain these results. We have previously noted that the maximal chemotactic response elicited in eosinophils by 5-oxo-ETE is substantially greater than the responses elicited by a number of other eosinophil chemoattractants, including platelet-activating factor [7], eotaxin [42], and $\mathrm{PGD}_{2}$ [37]. It is also possible that the cats used in this part of the study had some degree of asthma, which is common in this species, and could have resulted in enhanced eosinophil responsiveness to 5-oxo-ETE.

The two compounds (230 and 264) that we had previously identified as potent antagonists of the human OXE receptor had only weak effects on the responses of feline granulocytes to 5-oxo-ETE and were only active at concentrations in excess of $1 \mu \mathrm{M}$. Moreover, high concentrations of these antagonists did not appreciably affect the chemoattractant effect of 5-oxo-ETE on feline granulocytes. This is probably due to differences between the protein sequences of the feline and human OXE receptors. Although both respond very well to 5-oxo-ETE, the antagonists presumably do not interact nearly as well with the feline receptor, the sequence of which is $75 \%$ 
identical to the human receptor. Species selectivity of antagonists has also been reported for other receptors. For example, a series of human $\mathrm{NK}_{1}$ receptor antagonists have at least 100 times greater affinity for the human receptor compared to the rat or mouse receptors, even though the protein sequences of the latter differ by only 5\% from the human receptor [44]. In contrast, the natural ligand substance $\mathrm{P}$ has similar effects on $\mathrm{NK}_{1}$ receptors from all three species. Species differences have also been observed for inhibitors of mPGES-1 (microsomal PGE 2 synthase). MF63 is a potent inhibitor of human mPGES-1, but fails to inhibit the rat and mouse orthologs of this enzyme [45].

In conclusion, 5-oxo-ETE is a highly potent activator of feline granulocytes and is much more potent than other eicosanoids, including $\mathrm{PGD}_{2}$ and $\mathrm{LTB}_{4}$, in activating feline eosinophils. Furthermore, 5-oxo-ETE is synthesized by feline leukocytes and is present in biologically relevant concentrations in BAL fluid from cats with experimentally induced asthma. These results would suggest that 5-oxo-ETE may be an important mediator in feline asthma, which is a common disease in this species. Selective antagonists targeting the feline OXE receptor would aid in unraveling the pathophysiological roles of 5-oxo-ETE in cats and could be useful therapeutic agents in treating allergic feline asthma. While current human OXE receptor antagonists have only modest inhibitory effects on 5-oxo-ETE-induced responses in the cat, further research to increase antagonist potency is warranted. More importantly, in view of the lack of OXERI orthologs in rodents, the cat could serve as an excellent animal model to investigate the pathophysiological role of 5-oxo-ETE in human asthma. 


\section{Acknowledgements}

This work was supported by the Canadian Institutes of Health Research (WSP; grants MOP-6254 and PPP-99490), the American Asthma Foundation (JR; grant 12-0049), and the National Heart, Lung, and Blood Institute (JR; grant R01HL081873). The Meakins-Christie LaboratoriesMUHC-RI are supported in part by a Center grant from Le Fond de la Recherche en Santé du Québec as well as by the J. T. Costello Memorial Research Fund. J.R. also acknowledges the National Science Foundation for the AMX-360 (grant CHE-90-13145) and Bruker 400 MHz (grant CHE-03-42251) NMR instruments. The content is solely the responsibility of the authors and does not necessarily represent the official views of the National Heart, Lung, and Blood Institute or the National Institutes of Health. 


\section{References}

[1] Powell WS, Gravelle F, Gravel S. Metabolism of 5(S)-hydroxy-6,8,11,14-eicosatetraenoic acid and other 5(S)-hydroxyeicosanoids by a specific dehydrogenase in human polymorphonuclear leukocytes. J.Biol.Chem. 1992;267:19233-41.

[2] Powell WS, Rokach J. The eosinophil chemoattractant 5-oxo-ETE and the OXE receptor. Prog.Lipid Res. 2013;52:651-65.

[3] Erlemann KR, Cossette C, Grant GE, Lee GJ, Patel P, Rokach J, et al. Regulation of 5hydroxyeicosanoid dehydrogenase activity in monocytic cells. Biochem.J. 2007;403:157-65. [4] Erlemann KR, Rokach J, Powell WS. Oxidative stress stimulates the synthesis of the eosinophil chemoattractant 5-oxo-6,8,11,14-eicosatetraenoic acid by inflammatory cells. J.Biol.Chem. 2004;279:40376-84.

[5] Graham FD, Erlemann KR, Gravel S, Rokach J, Powell WS. Oxidative stress-induced changes in pyridine nucleotides and chemoattractant 5-lipoxygenase products in aging neutrophils. Free Radic.Biol.Med. 2009;47:62-71.

[6] Grant GE, Rubino S, Gravel S, Wang X, Patel P, Rokach J, et al. Enhanced formation of 5oxo-6,8,11,14-eicosatetraenoic acid by cancer cells in response to oxidative stress, docosahexaenoic acid and neutrophil-derived 5-hydroxy-6,8,11,14-eicosatetraenoic acid. Carcinogenesis. 2011;32:822-8.

[7] Powell WS, Chung D, Gravel S. 5-Oxo-6,8,11,14-eicosatetraenoic acid is a potent stimulator of human eosinophil migration. J.Immunol. 1995;154:4123-32.

[8] Powell WS, Gravel S, MacLeod RJ, Mills E, Hashefi M. Stimulation of human neutrophils by 5-oxo-6,8,11,14- eicosatetraenoic acid by a mechanism independent of the leukotriene $\mathrm{B}_{4}$ receptor. J.Biol.Chem. 1993;268:9280-6. 
[9] O'Flaherty JT, Kuroki M, Nixon AB, Wijkander J, Yee E, Lee SL, et al. 5-Oxo-

eicosatetraenoate is a broadly active, eosinophil- selective stimulus for human granulocytes.

J.Immunol. 1996;157:336-42.

[10] Schwenk U, Schröder JM. 5-Oxo-eicosanoids are potent eosinophil chemotactic factors functional characterization and structural requirements. J.Biol.Chem. 1995;270:15029-36.

[11] O'Flaherty JT, Cordes J, Redman J, Thomas MJ. 5-Oxo-eicosatetraenoate, a potent human neutrophil stimulus. Biochem.Biophys.Res.Commun. 1993;192:129-34.

[12] Czech W, Barbisch M, Tenscher K, Schopf E, Schröder JM, Norgauer J. Chemotactic 5-oxoeicosatetraenoic acids induce oxygen radical production, $\mathrm{Ca}^{2+}$-mobilization, and actin reorganization in human eosinophils via a pertussis toxin-sensitive G-protein. J.Invest.Dermatol. 1997;108:108-12.

[13] Dallaire MJ, Ferland C, Page N, Lavigne S, Davoine F, Laviolette M. Endothelial cells modulate eosinophil surface markers and mediator release. Eur.Respir.J. 2003;21:918-24. [14] Muro S, Hamid Q, Olivenstein R, Taha R, Rokach J, Powell WS. 5-oxo-6,8,11,14eicosatetraenoic acid induces the infiltration of granulocytes into human skin. J Allergy Clin.Immunol. 2003;112:768-74.

[15] Bäck M, Powell WS, Dahlén SE, Drazen JM, Evans JF, Serhan CN, et al. International Union of Basic and Clinical Pharmacology. Update on Leukotriene, Lipoxin and Oxoeicosanoid Receptors: IUPHAR Review 7. Br.J.Pharmacol. 2014.

[16] Hosoi T, Koguchi Y, Sugikawa E, Chikada A, Ogawa K, Tsuda N, et al. Identification of a novel eicosanoid receptor coupled to $\mathrm{G}_{\mathrm{i} / \mathrm{o}}$. J.Biol.Chem. 2002;277:31459-65.

[17] Jones CE, Holden S, Tenaillon L, Bhatia U, Seuwen K, Tranter P, et al. Expression and characterization of a 5-oxo-6E,8Z,11Z,14Z-eicosatetraenoic acid receptor highly expressed on human eosinophils and neutrophils. Mol Pharmacol. 2003;63:471-7. 
[18] Takeda S, Yamamoto A, Haga T. Identification of a G protein-coupled receptor for 5-oxoeicosatetraenoic acid. Biomedical Research-Tokyo. 2002;23:101-8.

[19] Sturm GJ, Schuligoi R, Sturm EM, Royer JF, Lang-Loidolt D, Stammberger H, et al. 5-Oxo6,8,11,14-eicosatetraenoic acid is a potent chemoattractant for human basophils. J.Allergy Clin.Immunol. 2005;116:1014-9.

[20] Iikura M, Suzukawa M, Yamaguchi M, Sekiya T, Komiya A, Yoshimura-Uchiyama C, et al. 5-Lipoxygenase products regulate basophil functions: 5-Oxo-ETE elicits migration, and leukotriene B(4) induces degranulation. J.Allergy Clin.Immunol. 2005;116:578-85.

[21] Khanapure SP, Shi XX, Powell WS, Rokach J. Total synthesis of a potent proinflammatory 5-oxo-ETE and its 6,7-dihydro biotransformation product. Journal of Organic Chemistry. 1998;63:337-42.

[22] Zamboni R, Rokach J. Stereospecific synthesis of 5S-HETE, 5R-HETE and their transformation to 5(+/-)HPETE. Tetrahedron Lett. 1983;24:999-1002. [23] Zamboni R, Rokach J. Simple Efficient Synthesis of $\mathrm{LTB}_{4}$ and 12-epi-LTB 4 . Tetrahedron Letters. 1982;23:2631-4.

[24] Gore V, Gravel S, Cossette C, Patel P, Chourey S, Ye Q, et al. Inhibition of 5-oxo-6,8,11,14eicosatetraenoic acid-induced activation of neutrophils and eosinophils by novel indole OXE receptor antagonists. J.Med.Chem. 2014;57:364-77.

[25] Hamberg M, Samuelsson B. On the specificity of the oxygenation of unsaturated fatty acids catalyzed by soybean lipoxidase. J.Biol.Chem. 1967;242:5329-35.

[26] Norris Reinero CR, Decile KC, Berghaus RD, Williams KJ, Leutenegger CM, Walby WF, et al. An experimental model of allergic asthma in cats sensitized to house dust mite or bermuda grass allergen. Int.Arch.Allergy Immunol. 2004;135:117-31. 
[27] Powell WS. Precolumn extraction and reversed-phase high-pressure liquid chromatography of prostaglandins and leukotrienes. Anal.Biochem. 1987;164:117-31.

[28] Khanapure SP, Shi XX, Powell WS, Rokach J. The total synthesis of tritiated and deuterated 5-oxo-ETE, a novel inflammatory mediator. Journal of Organic Chemistry. 1998;63:4098-102.

[29] Mesaros C, Lee SH, Blair IA. Targeted quantitative analysis of eicosanoid lipids in biological samples using liquid chromatography-tandem mass spectrometry. J Chromatogr B. 2009;877:2736-45.

[30] Singh G, Gutierrez A, Xu KY, Blair IA. Liquid chromatography/electron capture atmospheric pressure chemical ionization/mass spectrometry: Analysis of pentafluorobenzyl derivatives of biomolecules and drugs in the attomole range. Anal Chem. 2000;72:3007-13. [31] Monneret G, Li H, Vasilescu J, Rokach J, Powell WS. 15-Deoxy- $\Delta^{12,14}$-prostaglandins $\mathrm{D}_{2}$ and $J_{2}$ are potent activators of human eosinophils. $J$ Immunol. 2002;168:3563-9.

[32] Powell WS, MacLeod RJ, Gravel S, Gravelle F, Bhakar A. Metabolism and biologic effects of 5-oxoeicosanoids on human neutrophils. J.Immunol. 1996;156:336-42.

[33] Davis G, Thornalley PJ. Free radical production from the aerobic oxidation of reduced pyridine nucleotides catalysed by phenazine derivatives. Biochim.Biophys.Acta. 1983;724:45664.

[34] Zhang Y, Styhler A, Powell WS. Synthesis of 5-oxo-6,8,11,14-eicosatetraenoic acid by human monocytes and lymphocytes. J.Leukoc.Biol. 1996;59:847-54.

[35] Blättermann S, Peters L, Ottersbach PA, Bock A, Konya V, Weaver CD, et al. A biased ligand for OXE-R uncouples $\mathrm{G} \alpha$ and $\mathrm{G} \beta \gamma$ signaling within a heterotrimer. Nat.Chem.Biol. 2012;8:631-8. 
[36] Powell WS, Zhang Y, Gravel S. Effects of phorbol myristate acetate on the synthesis of 5oxo-6,8,11,14-eicosatetraenoic acid by human polymorphonuclear leukocytes. Biochemistry. $1994 ; 33: 3927-33$.

[37] Monneret G, Gravel S, Diamond M, Rokach J, Powell WS. Prostaglandin $\mathrm{D}_{2}$ is a potent chemoattractant for human eosinophils that acts via a novel DP receptor. Blood. 2001;98:1942-8. [38] Powell WS, Gravel S, Halwani F. 5-oxo-6,8,11,14-Eicosatetraenoic Acid Is a Potent Stimulator of L- Selectin Shedding, Surface Expression of CD11b, Actin Polymerization, and Calcium Mobilization in Human Eosinophils. Am.J.Respir.Cell Mol.Biol. 1999;20:163-70. [39] Hosoi T, Sugikawa E, Chikada A, Koguchi Y, Ohnuki T. TG1019/OXE, a Galpha(i/o)protein-coupled receptor, mediates 5-oxo-eicosatetraenoic acid-induced chemotaxis. Biochem.Biophys.Res.Commun. 2005;334:987-95. [40] Parekh AB, Putney JW, Jr. Store-operated calcium channels. Physiol Rev. 2005;85:757-810. [41] O'Flaherty JT, Kuroki M, Nixon AB, Wijkander J, Yee E, Lee SL, et al. 5-oxo-eicosanoids and hematopoietic cytokines cooperate in stimulating neutrophil function and the mitogenactivated protein kinase pathway. J.Biol.Chem. 1996;271:17821-8.

[42] Powell WS, Ahmed S, Gravel S, Rokach J. Eotaxin and RANTES enhance 5-oxo-6,8,11,14eicosatetraenoic acid- induced eosinophil chemotaxis. J Allergy Clin.Immunol. 2001;107:272-8. [43] Dye JA, McKiernan BC, Rozanski EA, Hoffmann WE, Losonsky JM, Homco LD, et al. Bronchopulmonary disease in the cat: historical, physical, radiographic, clinicopathologic, and pulmonary functional evaluation of 24 affected and 15 healthy cats. J.Vet.Intern.Med. 1996;10:385-400.

[44] Saria A. The tachykinin NK1 receptor in the brain: pharmacology and putative functions. Eur.J.Pharmacol. 1999;375:51-60. 
[45] Côté B, Boulet L, Brideau C, Claveau D, Ethier D, Frenette R, et al. Substituted

phenanthrene imidazoles as potent, selective, and orally active mPGES-1 inhibitors. Bioorg Med

Chem Lett. 2007;17:6816-20. 


\section{Captions for figures}

Figure 1. Biosynthesis and biological effects of 5-oxo-ETE. 5-Oxo-ETE is synthesized by oxidation of the 5-LO product 5S-HETE by 5-HEDH in the presence of NADP+. Its synthesis is limited by the availability of $\mathrm{NADP}^{+}$, which can be generated from NADPH in the presence of phenazine methosulfate (PMS) or by activation of the respiratory burst by phorbol myristate acetate (PMA). 5-Oxo-ETE activates eosinophils and neutrophils via the OXE receptor, which can be blocked in human cells by the selective antagonists 230 and 264. Px, peroxidase.

\section{Figure 2. Biosynthesis of 5-oxo-ETE by feline peripheral blood leukocytes. Feline leukocytes} (2.5 x $10^{6}$ cells in $\left.0.5 \mathrm{~mL}\right)$ were preincubated with PMS $(50 \mu \mathrm{M})$ for $5 \mathrm{~min}$, followed by incubation with 5S-HETE ( $4 \mu \mathrm{M})$ for an additional $10 \mathrm{~min}$. A: the products were analyzed by precolumn extraction-RP-HPLC as described in Materials and Methods, using 13-HODE (30 ng) as an internal standard (int std). 5-HETE and 13-HODE were detected at $235 \mathrm{~nm}$, whereas 5-oxoETE was detected at $280 \mathrm{~nm}$. The identities of 5-HETE and 5-oxo-ETE were confirmed by comparison of their retention times and UV spectra with those of authentic synthetic standards. The scales for the $\mathrm{Y}$-axis for 235 and $280 \mathrm{~nm}$ are identical, However, the peak for 5-HETE is offscale. The ratio for the peak heights (5-HETE/5oxo-ETE) is 100:9. B: UV spectrum of the product (i.e. 5-oxo-ETE) with a $t_{\mathrm{R}}$ of $6.34 \mathrm{~min}$, The data shown are representative of six separate experiments with similar results.

\section{Figure 3. Biosynthesis of LTB4, 5-HETE, and 5-oxo-ETE by BAL cells from cats with} experimentally induced asthma. Feline BAL cells were separated into two fractions based on adherence to plastic. Cells from each of these fractions were then incubated with AA $(20 \mu \mathrm{M})$, 


\begin{abstract}
A23187 $(5 \mu \mathrm{M})$, and PMA (100 $\mathrm{nM})$ for $30 \mathrm{~min}$ as described in Materials and Methods. The amounts of $\mathrm{LTB}_{4}$ (open bars), 5-HETE (hatched bars), and 5-oxo-ETE (filled bars) were determined by precolumn extraction-RP-HPLC using $\mathrm{PGB}_{2}$ as an internal standard. The values for $\mathrm{LTB}_{4}$ do not include its 6-trans isomers or its metabolites. All values are means $\pm \mathrm{SE}(\mathrm{n}=6)$. For adherent cells the amounts of $\mathrm{LTB}_{4}$ were less than 5-HETE and 5-oxo-ETE $(\mathrm{p}<0.05)$, whereas for non-adherent cells the amounts of 5-HETE were greater than those of $\mathrm{LTB}_{4}$ and 5oxo-ETE $(\mathrm{p}<0.05)$.
\end{abstract}

Figure 4. Measurement of 5-oxo-ETE in feline BAL fluid by LC-MS. Deuterium-labeled 5oxo-ETE (d4-5oETE) was added to feline BAL fluid, followed by extraction with methyl-t-butyl ether, derivatization with pentafluorobenzyl bromide, and analysis by LC-MS-MS as described in Materials and Methods. Daughter ions at m/z 207 (A) and 203 (B) were monitored for d4-5-oxoETE and unlabeled 5-oxo-ETE, respectively. The chromatogram shown is representative of data from 7 cats.

\title{
Figure 5. Effects of 5-oxo-ETE, $\mathrm{PGD}_{2}$, and $\mathrm{LTB}_{4}$ on calcium mobilization in feline
}

leukocytes. Unfractionated feline leukocytes were treated with allophycocyanin-labeled antiCD49d and fluo-3 acetoxy methyl ester and analyzed by flow cytometry as described in Materials and Methods. A: Dot plot showing the separation of eosinophils and neutrophils based on side scatter and anti-CD49d staining. Eosinophil (B) and neutrophil (C) populations were further characterized by their forward scatter properties. Calcium mobilization was elicited in eosinophils by addition of $10 \mathrm{nM}$ 5-oxo-ETE (D, H), $100 \mathrm{nM} \mathrm{PGD} 2(\mathbf{E})$, or $10 \mathrm{nM} \mathrm{LTB}_{4}(\mathrm{I})$. Calcium mobilization in neutrophils was also elicited by addition of $10 \mathrm{nM}$ 5-oxo-ETE (F, J) and 
$10 \mathrm{nM} \mathrm{LTB}_{4}(\mathbf{K})$ but not by $100 \mathrm{nM} \mathrm{PGD}(\mathbf{G})$. A23187 $(10 \mu \mathrm{M})$ was added 1 min after the addition of agonist to evaluate the maximal calcium response for each sample. The data are representative of four experiments with similar results performed using leukocytes from four different cats. The data in panels $\mathrm{D}$ to $\mathrm{G}$ and panels $\mathrm{H}$ to $\mathrm{K}$ are from two different cats.

\author{
Figure 6. Effects of 5-oxo-ETE and other eicosanoids on actin polymerization and \\ chemotaxis in feline leukocytes. Feline leukocytes stained with anti-CD49d were incubated with \\ 5-oxo-ETE $(\bullet), \operatorname{LTB}_{4}(\Delta)$, or $\mathrm{PGD}_{2}(\boldsymbol{\nabla})$ for $20 \mathrm{~s}$. The cells were then labeled with NBD- \\ phallacidin and F-actin levels were evaluated in eosinophils (A) and neutrophils (B) using flow \\ cytometry. Granulocyte migration $(\mathbf{C})$ in response to 5-oxo-ETE $(\bullet)$ and $\operatorname{LTB}_{4}(\Delta)$, was measured \\ using microchemotaxis chambers as described in Materials and Methods. The results are means \pm \\ SE of results from at least 4 independent experiments. The data are expressed as percentages of \\ the maximal response to 5-oxo-ETE.
}

Figure 7. Structures of OXE receptor antagonists.

Figure 8. Effects of the OXE receptor antagonists 230 and 264 on 5-oxo-ETE-induced actin polymerization and cell migration in granulocytes. Feline leukocytes $(\bullet, \mathbf{\Lambda})$ stained with antiCD49d were preincubated with $230(\bullet, \circ)$ or $264(\Delta, \Delta)$ for 5 min at $25{ }^{\circ} \mathrm{C}$, followed by incubation with 5-oxo-ETE $(10 \mathrm{nM})$ for a further $20 \mathrm{~s}$. The cells were then labeled with NBDphallacidin and F-actin levels were evaluated in eosinophils (A) and neutrophils (B) using flow cytometry. Data from human granulocytes from a previous study [24], are shown for comparison. C: 5-Oxo-ETE-induced leukocyte migration was evaluated using microchemotaxis chambers as 
described in Materials and Methods. Vehicle $(\bullet), 230(10 \mu \mathrm{M} ; \Delta)$, or $264(10 \mu \mathrm{M} ; \nabla)$ were added to both the top and bottom chambers). The values are means $\pm \operatorname{SE}(n=4)$. 

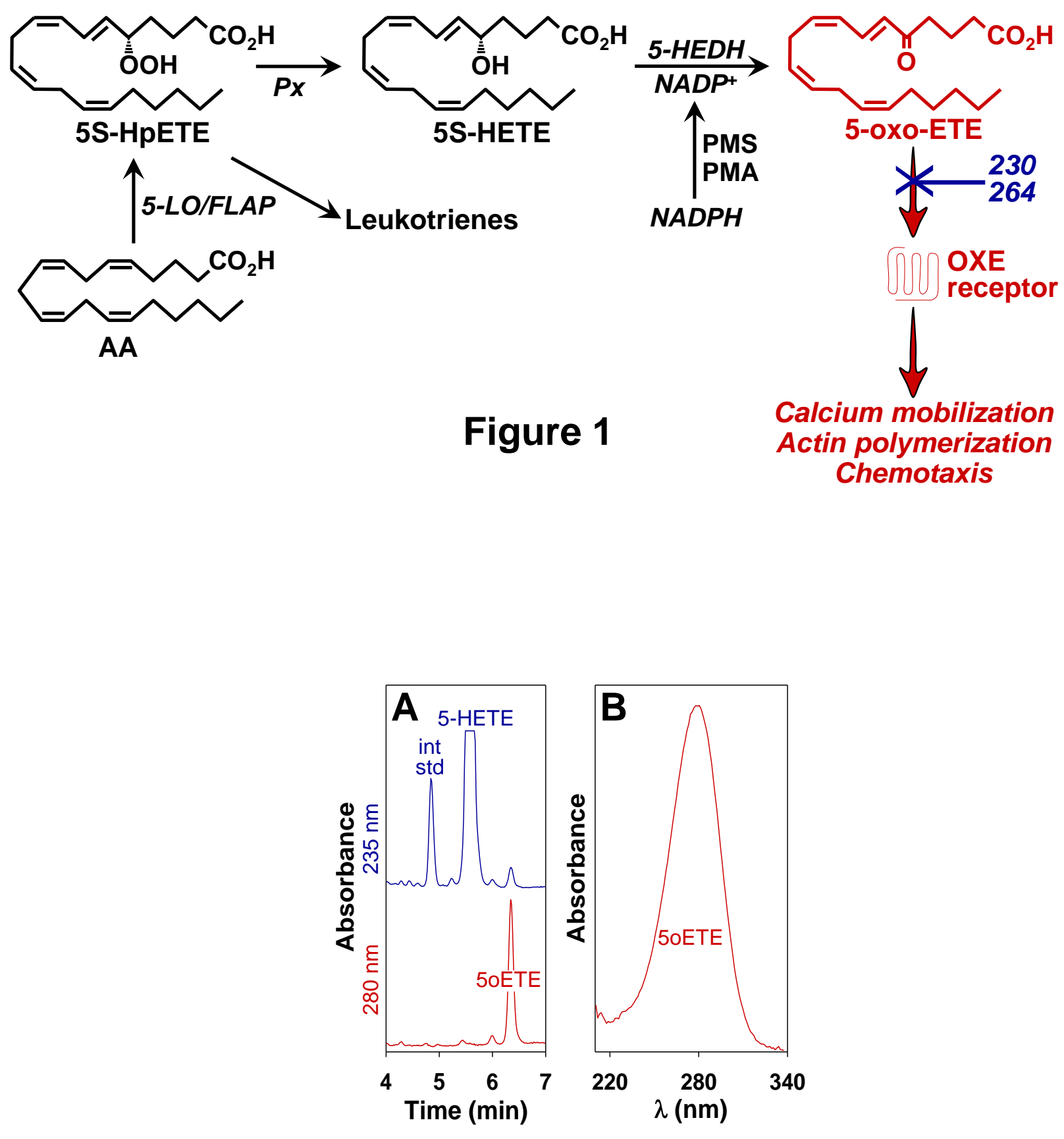

Figure 2 


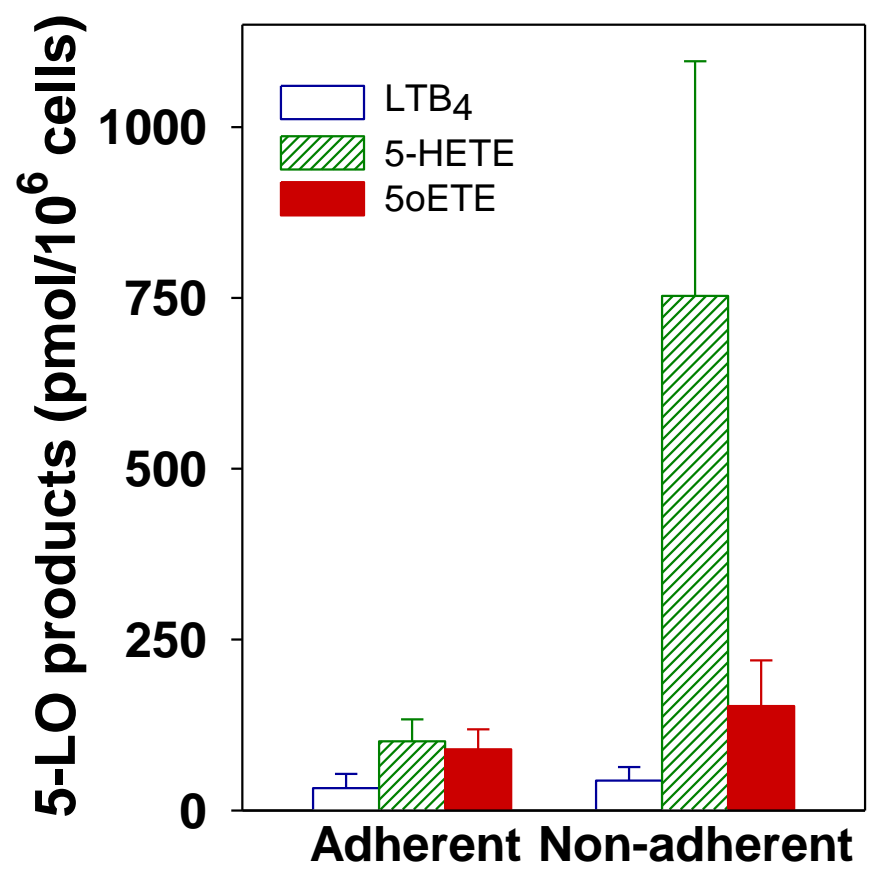

Figure 3

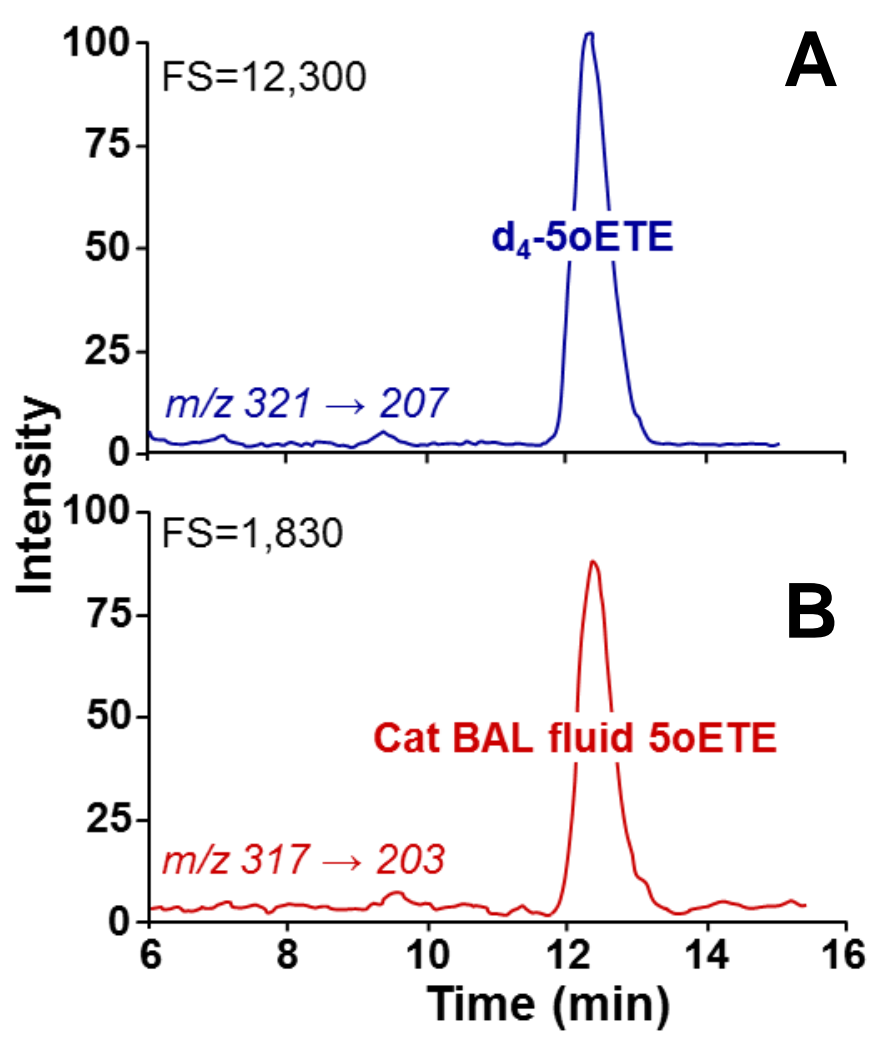

Figure 4 

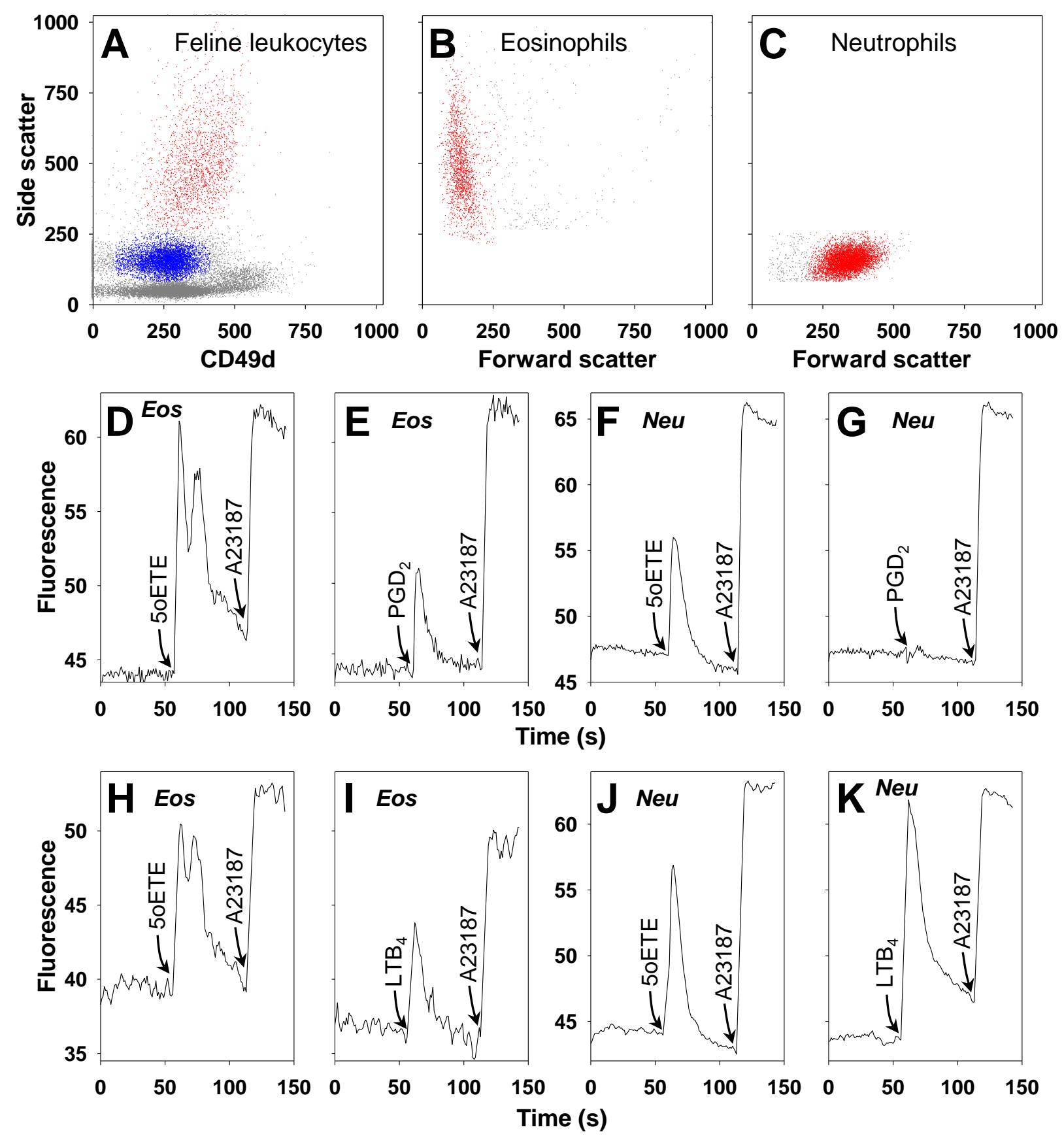

Figure 5 


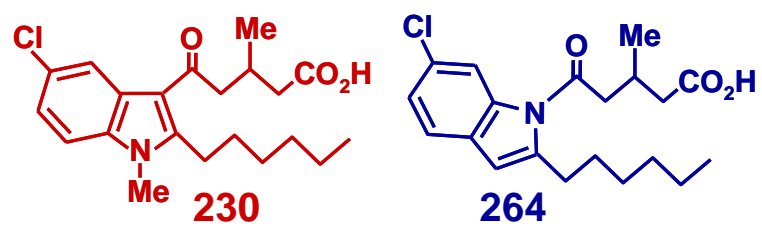

Figure 7
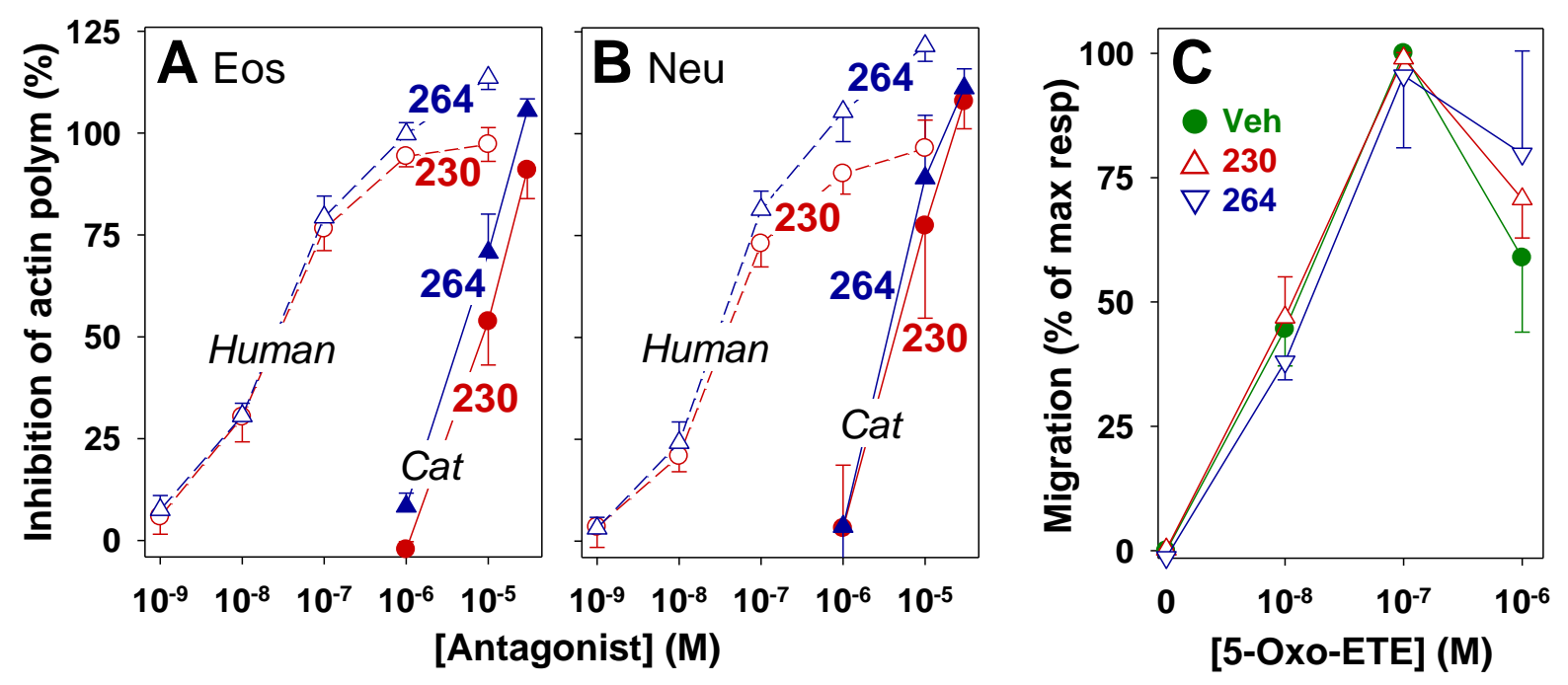

Figure 8 